\title{
SAFETY PROJECT: SENTINEL-1 BASED TOOLS FOR GEOHAZARDS MONITORING AND MANAGEMENT
}

\author{
O. Monserrat ${ }^{1}$, A. Barra ${ }^{1}$, G. Herrera ${ }^{2}$, S. Bianchini ${ }^{3}$, C. Lopez ${ }^{4}$, R. Onori ${ }^{5}$, P. Reichenbach ${ }^{6}$, R. Sarro ${ }^{2}$, R. M. Mateos ${ }^{8}$, L. Solari \\ ${ }^{3}$, S. Ligüérzana ${ }^{9}$, I. P. Carralero ${ }^{7}$ * \\ Centre Tecnològic de Telecomunicacions de Catalunya (CTTC/CERCA), Geomatics Division, Castelldefels, Spain - \\ (omonserrat, abarra, mcrosetto)@ cttc.cat. \\ 2 Geohazards InSAR Laboratory and Modeling Group (InSARlab), Geoscience Research Department, Geological \\ Survey of Spain (IGME), Alenza 1, 28003 Madrid, Spain. E-Mails: (g.herrera, m.bejar)@igme.es. \\ 3 Earth Sciences Department, University of Firenze, Via La Pira, 4, I-50121 Firenze, Italy - (silvia.bianchini, \\ lorenzo.solari, sandro.moretti)@unifi.it. \\ 4 Observatorio Geofísico Central, Instituto Geográfico Nacional (IGN), Madrid, Spain. - (egalonso, \\ clmoreno)@fomento.es. \\ 5 Italian Civil Protection Department, Rome 00189, Italy - (roberta.Onori, Paola.Pagliara)@ protezionecivile.it. \\ $6 \quad$ Istituto di Ricerca per la Protezione Idrogeologica (IRPI), National Research Council (CNR), Via Madonna Alta \\ 126, I-06128 Perugia, Italy - (paola.reichenbach, francesca.ardizzone)@irpi.cnr.it. \\ 7 Dirección General de Seguridad y Emergencias, Consejería de Política Territorial, Seguridad y Sostenibilidad, \\ Gobierno de Canarias, Spain - (icarjai, jparlopa)@gobiernodecanarias.org. \\ 8 Geological Survey of Spain (IGME).Urb. Alcázar del Genil, 4-Edif. Bajo, 18006 Granada, Spain - \\ rm.mateos@igme.es \\ Centro Nacional de Información Geográfica, Instituto Geográfico Nacional, C/ General Ibáñez de Ibero, 3. Madrid, \\ Spain. - cnig.slr@fomento.es.
}

\section{Commission VI, WG VI/4}

KEY WORDS: Safety, Monitoring, Geohazard, SAR, PSI

\begin{abstract}
:
SAFETY is a two-years European project started the 1st January 2016 and ended the 1st January 2018. The general aim of the project was to develop a methodology and tools in order to exploit Sentinel-1 data for detecting and monitoring the activity state of geohazards (e.g. landslides, volcanic and subsidence) and evaluating their impact on built-up areas and infrastructure networks, at a regional scale. The products of the methodology must support Civil Protection Authorities (CPA) in the risk management activities at a regional scale. In this contest, a strong effort has been spent to generate products that must be operative: reliable and easily to read by users who are not familiar with radar data. The developed procedure is fast, periodically repeatable, and case-adaptable. The methodology, allows the full exploitation of Sentinel-1 constellation data (wide area coverage, high temporal repeatability, freely available data) making feasible long term monitoring plannings. Moreover a free software tool for the Sentinel-1 SAR data processing has been developed. This work presents the developed methodology, through some images of the most significant results obtained over the two test sites of the project (the Canary Island, in Spain, and the Volterra municipality, in Italy), and explains both the strengths and the main lessons learnt for the future steps.
\end{abstract}

\section{INTRODUCTION}

\subsection{The Safety Project}

Safety is a two years project (safety.cttc.es), funded under the 2015 ECHO (European Commission's Humanitarian aid and Civil Protection department) call "Prevention and preparedness projects in Civil Protection and marine pollution", which started the 1st of January 2016 (Monserrat et al.,2017) .

The aim of Safety was to improve the exploitation of Sentinel-1 data for the geohazads monitoring and the Civil Protection Authorities' (CPA) activities of risk management, at a regional scale. This global goal has been achieved by: a) developing a simple and semi-automatic methodology to produce regionalscale maps of geo-hazards activity and urban impact; b) implementing a new open source software tool. The consortium of the project was composed by eight partners: the Centre
Tecnològic de Telecomunicacions de Catalunya (CTTC), the Instituto Geológico y Minero de España (IGME), the Instituto Geográfico Nacional (IGN) and the Dirección General de Seguridad y Emergencias of Spain, the Italian and Spanish Civil Protections, the Earth Science Department of University of Florence (UNIFI)(Italy) and the Italian National Research Council (Cnr).

\subsection{State of the art}

In the last 25 years, the satellite Synthetic Aperture Radar (SAR) Differential Interferometry (DInSAR) has given a great contribution in the detection and monitoring of geohazards like landslides (Farina et al., 2006; Herrera et al., 2009; Barra et al. 2016; Béjar-Pizarro et al. 2017), subsidences (Ferretti et al., 2004; Zerbini et al., 2007; Béjar-Pizarro et al. 2016) or volcanos (Massonet et al., 2000). Since the first use of the

\footnotetext{
* Corresponding author
} 
DInSAR technique, with the Seasat satellite data (Gabriel et al. 1989), several methodologies and processing tools have been developed. Some examples are: the interferometric analysis (Massonnet and Feigl, 1998; Rosen et al., 2000; Barra et al. 2016); the multi-interferometry analysis (Berardino et al. 2002; Mora et al., 2003; Biescas et al., 2007, Crosetto et al.,2011) and several implementations of the Persistent Scatterer Interferometry (PSI) technique. A review of all the PSI implementations is available in Crosetto et al. (2016). Moreover, the availability of SAR satellite data, with different spatial and temporal resolutions and acquisition characteristics, is increased a lot. However, the DInSAR is still not fully integrated in the existing CPA risk management and monitoring structures as a constant and periodical complementary data. One of the main reason is the difficulty of the technique: on one hand the interpretation of the DInSAR derived products (like the deformation velocity maps) can be misleading for a final user who is not familiar with the DInSAR technique. On the other hand, the number of information is huge and not feasible to be used in an easy and fast way.

\subsection{Specific aims}

As introduced in the previous section, the interpretation of the deformation maps derived by the DInSAR technique can be complex and requires a deep knowledge of the technique (Ferretti et al. 2007; Notti et al. 2014 and 2015). Resuming, the main reason of the technique complexity are: a) the geometric limitation of SAR acquisition and the capability of measuring deformation only in the line of sight of the satellite; b) the spatio-temporal noise and c) the huge number of information that can make difficult the identification of the interesting information, mainly working at a regional level.

Usually, the CPAs who manage with the geohazard monitoring and management do not have this background knowledge. Moreover, CPAs need maps containing clear and selected useful information. In this contest, the specific objective of the methodology was to produce maps that had to be:

1. Readable
2. Reliable
3. Easy to be exploited at a regional scale

\subsection{Why Sentinel-1}

Sentinel-1 (S1) is a constellation of two radar imaging satellites (S1A and S1B), launched respectively in 2014 and 2016 (Rucci et al., 2012), and it represent a great step forward in the availability of C-band data. In fact, it ensures a regular worldwide acquisition, with a high temporal sampling (acquiring an image every 6 days in Europe), and it provides free data, available to all users without limitations. Moreover, the acquisition method (TOPS) delivers images covering wide areas $\left(250 \times 250 \mathrm{~km}^{2}\right)$. These characteristics allow accomplishing long term monitoring planning, at a regional scale, in any place of the world.

\subsection{Test Sites}

The selected test sites were the Volterra Municipality (Italy) and the Canary Islands (La Gomera, Tenerife and Gran Canaria, Spain). The two locations allow evaluating the methodology in different environmental conditions considering various scenario of applications. In the Canary Islands the main geohazards are volcanic and rock-fall whereas in the Volterra Municipality are landslides. Moreover, the geo-lithological setting and the land coverage of the two sites determine a very different radar response in terms of coherence. Some images of the most significant results obtained over the two test sites are presented in the following, with the aim of describing the methodology.

\section{METHODOLOGY}

\subsection{Overview}

As presented in the flowchart of Figure 1, the developed methodology can be resumed in three main blocks:

1. Processing block: it consists in the processing of Sentinel-1 data in order to obtain the preliminary deformation map.

2. Post-processing block: it consists in the simplification of the preliminary deformation map, in order to improve both the reliability and the readability. The outputs of this block are the final Deformation Activity Map (DAM) and the Active Deformation Areas (ADA) map.

3. Geohazard management block: it consists in the use of the ADA map together with other information in order to update the existing knowledge and derive useful maps for the geohazard management activities. The main output of this block are the Geohazard Activity Map (GAM) and the Vulnerable Element Activity Map (VEAM).

The methodology is supposed to be periodically performed in order to have a periodical update of the deformation activities (monitoring). The blocks 1 and 2 can be applied to any PSI derived deformation map, allowing any user to take advance of this information without the need of having the processing capabilities. Nevertheless, the best performances of the methodology, considering its original aim, are obtained using Sentinel-1 satellite data. Moreover, the blocks 1 and 2 can be easily performed in a Geographic Information System (GIS) environment, like the open source software QGIS ${ }^{\circledR}$.

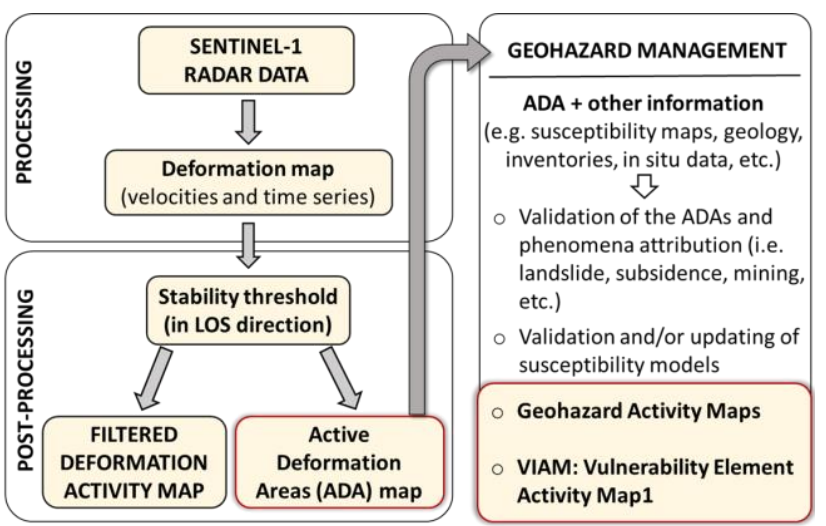

Figure 1. Workflow of the developed methodology. The main products of the methodology are highlighted by the red squares.

\subsection{Processing}

In the Safety project, a software tool has been implemented to process Sentinel-1 SLC images and derive the deformation map. The deformation map is a map of distributed punctual measures, where, for each point, are estimated the annual linear velocity and the time series of deformation. As explained in the introducing session, several DInSAR processing techniques to derive deformation map by satellite SAR data exists. The technique proposed in Safety, is an approach of the Persistent 
Scatterer Interferometry chain of the Geomatics Division of CTTC (PSIG) described in Devanthéry et al., 2014. These developed tools are free and available to all the institutions that support the CPAs activities, allowing them to periodical generate the deformation maps.

\subsection{Post-processing}

The aim of this block is to simplify the use and interpretation of the preliminary deformation map. On one hand, a filtering is applied to reduce the spatio-temporal noise and generate the final filtered Deformation Activity Map (DAM). On the other hand, a semi-automatic procedure allows extracting the most significant detected Active Deformation Areas (ADA). Figure 2 shows the results of this block over the test site of Canary Island and Figure 3 a detail in the Teide and Pico Viejo zone, in Tenerife. The ADA map (Figure 2b), on one hand allows a rapid regional scale overview, for the visualization and localization of the detected active areas; on the other hand, it resumes the most relevant information (e.g., the mean annual velocity, the accumulated deformation and the Quality Index that estimate the reliability level of the ADA information). The DAM maintains the detailed information of the velocity and the TS for each PS (Figure $3 a$ and $3 b$ ). In this sense, the DAM and ADA maps (Figure 2 and Figure 3 ) allow to have information at two level of detail. We refer to Barra et al., 2017 for a detailed description of this block. The ADA map is one of the main output of the methodology, since it is used as input for the generation of the other products (block 3), allowing the periodical update of the activity information.
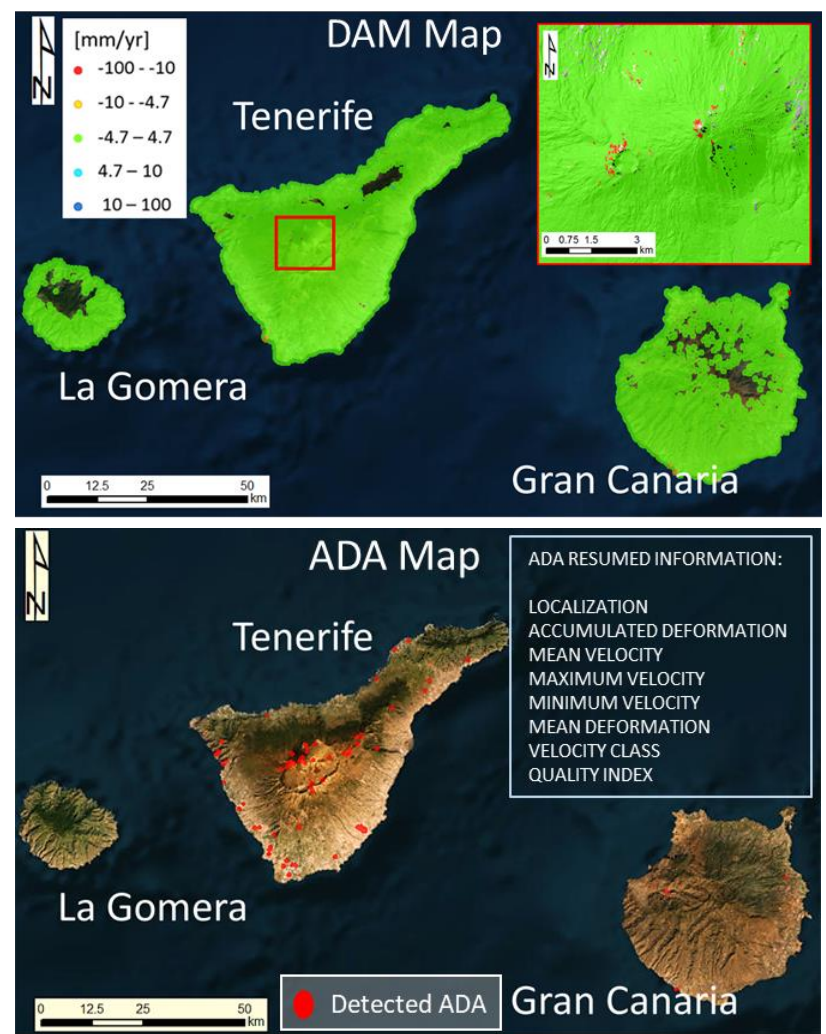

Figure 2. Results of the block 3 over the three studied Canary Island: La Gomera, Tenerife and Gran Canaria. a) The filtered DAM in terms of annual velocity (mm/yr). A detail of the Teide and Pico Viejo zone of Tenerife is shown in the upper-right red square. b) The ADA map with the list of the summarized information for each ADA in the upper-right square.
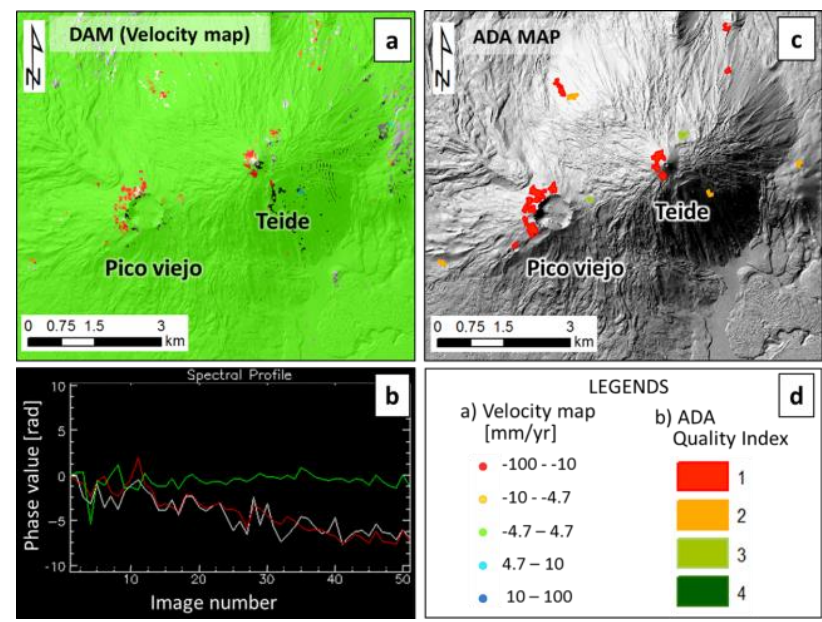

Figure 3. A detail of the results in the Teide and Pico Viejo zone of Tenerife. a) The DAM in terms of annual velocity (see the legend in d)). b) Examples of three neighbouring deformation Time Series (TS), the green one shows not detected deformation, the white and red ones are active points (PS) belonging to an extracted ADA in the Teide cone. c) The extracted ADA classified by their Quality Index (see the legend in d)).

\subsection{Geohazard Management}

In this block, the ADA map is integrated with other data in a Geographic Information System (GIS). This integration, on one hand allows an interpretation of each ADA in order to attribute the nature of the detected deformation (e.g. antropic, subsidence, landslide, ecc.), resulting in the Geohazard Activity Maps (GAM). On the other hand, it allows to periodical update the existing information, such as inventory or susceptibility maps. Figure 4 shows an example of updating an existing Landslide Inventory Map (LIM), with the ADA information, in the Volterra city (located in the Molise test-site). The yellow arrow indicate a landslide that was classified as dormant in the existing LIM: you can see that an Active Deformation Area is overlapping the landslide, indicating an active movement.

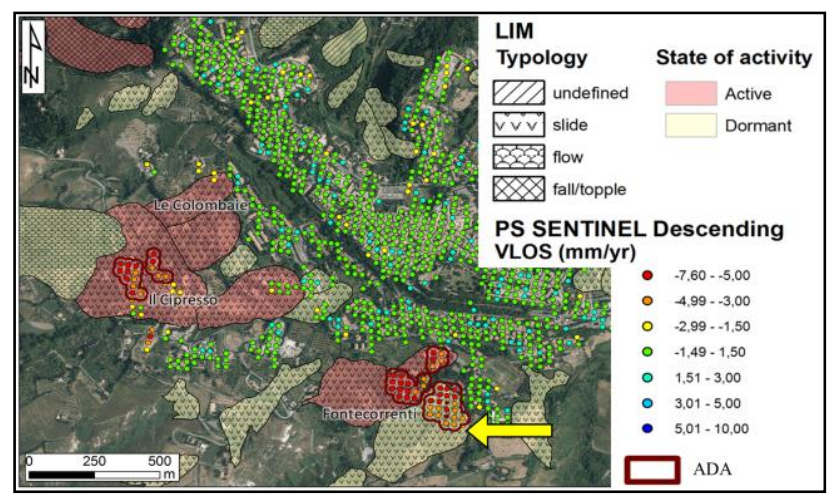

Figure 4. A detail of the results over the city of Volterra (in the Tuscany Region test-site). An example of intersecting different information layers to update the existing inventory (LIM) and generate the Geohazard Activity Map (GAM).

Then, the intersection of the GAM with an inventory of the exposed elements (e.g. infrastructures, streets, houses, hospitals) provides the Vulnerable Element Activity Map (VEAM) (Figure 5). This can be easily done in a GIS environment. 


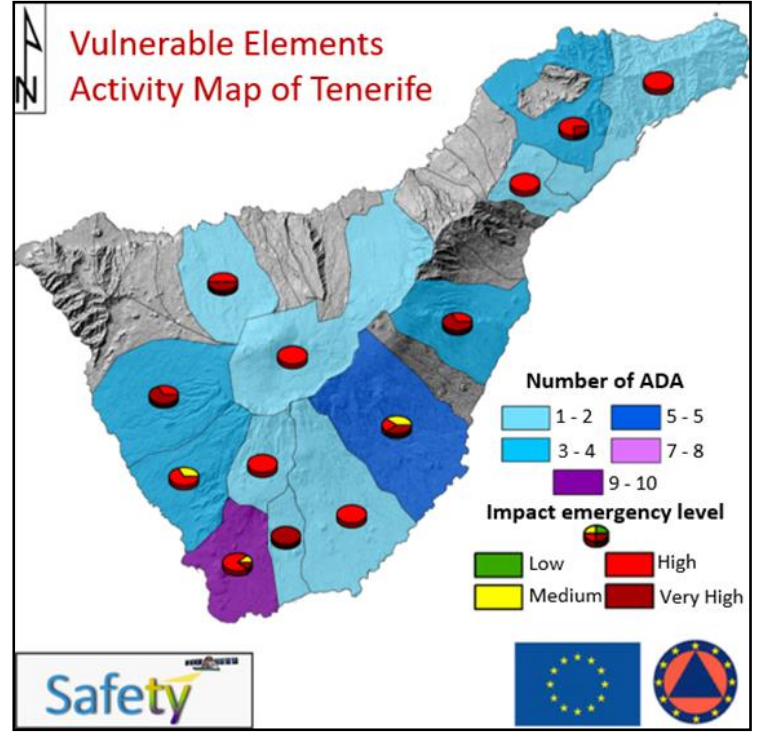

Figure 5. The VEAM of Tenerife.

The VEAM summarizes the number of the elements affected by active geological processes for each territorial unit. The exposed elements are classified on the base of their strategic role in the different phases of the CPA risk management activities. The classification of the affected element with the higher strategic role gives the impact emergency level of the territorial unit. We refer to Solari et al., 2017 for a detailed description of this block.

\section{CONCLUSIONS}

This paper aims at presenting the results obtained in the Safety project. The aim of the project was to implement a methodology and develop tools in order to allow the use of the PSI technique as a constant input in the regional scale geohazard monitoring and management. The developed methodology simplifies the use of the PSI products by extracting the most significant detected Active Deformation Areas (ADA) and resuming the relevant information. The ADA map is a simple product, feasible to be used by the CPAs and by all the users who are not used to work with SAR data, avoiding dangerous misunderstanding. The other products are maps derived by a step forward of interpretation. The Geohazard Activity Map (GAM) attributes the geological deformation process to each ADA. The Vulnerable Element Activity Map (VEAM) is a speedy assessment of the impact of the detected ADA on builtup areas and infrastructure networks. The input data are the open source Sentinel-1 SAR images. Sentinel-1 ensures a regular worldwide acquisition with a high temporal sampling, allowing to make long-term monitoring planning. All the products help to focalize and direct deeper analysis, monitoring activities or individuate critic situations. The Sentiinel-1 processing tools developed in Safety are free and available to all the institutions involved in the geohazard management. The described methodology and tools are nowadays being used by the IGN Volcano Monitoring System (VMS), in their activities of supporting the Canary Island Civil Protection in the volcanic risks management. In addition, the University of Florence, which is a competence centre of the Italian Civil Protection, is also using the methodology developed in Safety for the landslide risk monitoring in Tuscany and Valle d'Aosta regions (Italy). At the end of the project we confirm the strong regional to local scale monitoring potentialities of Sentinel-1. Anyway, step forewords have to be done in two main aspects: 1) The fully exploitation of the 6-12 days temporal sampling of Sentinel-1. The potentialities of landslide activity characterization by using the 6-12 days interferometric information of Sentinel-1 has been demonstrated in Barra et al., 2016,. A similar approach still needs to be automatized and assessed with a repeatable methodology. 2) SAFETY has identified the existing gap between the interest of the CPAs for using and implementing new products in their workflow and their technical limitation to produce such products. In this contest, in the geohazard management, is necessary an improvement of the links between different actors, like the scientific community, the hazard experts and the CPAs.

These objectives are two of the main aims of the new 2 years ECHO project U-Geohaz (2017/PREV/783169), started the $1^{\text {st }}$ of January 2018, which is born as a continuation of Safety.

\section{ACKNOWLEDGEMENTS}

This work has been funded by the European Commission, Directorate-General Humanitarian Aid and Civil Protection (ECHO), through the project Safety (Ref. ECHO/SUB/2015/718679/Prev02).

\section{REFERENCES}

Barra A, Monserrat O, Mazzanti P, Esposito C, Crosetto M, Scarascia Mugnozza G. 2016. First insights on the potential of Sentinel-1 for landslides detection. Geomat Natural Hazard and Risk. 7 (6) pp. 1874-1883.

Barra, A., Solari, L., Béjar-Pizarro, M., Monserrat, O., Bianchini, S., Herrera, G., Crosetto, M., González-Alonso, E., Mateos, R.M., Ligüerzana, S., López, C., Moretti, S. 2017. A Methodology to Detect and Update Active Deformation Areas Based on Sentinel-1 SAR Images. Remote Sens. 9(10), pp. 1002.

Béjar-Pizarro, M., Guardiola-Albert, C., García-Cárdenas, R. P., Herrera, G., Barra, A., López Molina, A., ... \& García-García, R. P., 2016. Interpolation of GPS and Geological Data Using InSAR Deformation Maps: Method and Application to Land Subsidence in the Alto Guadalentín Aquifer (SE Spain). Remote Sensing, 8(11), 965.

Béjar-Pizarro, M.; Notti, D.; Mateos, R.M.; Ezquerro, P.; Centolanza, G.; Herrera, G.; Bru, G.; Sanabria, M.; Solari, L.; Duro, J.; Fernández, J., 2017. Mapping Vulnerable Urban Areas Affected by Slow-Moving Landslides Using Sentinel-1 InSAR Data. Remote Sens., 9, 876.

Berardino, P., Fornaro, G., Lanari, R., Sansosti, E., 2002. A new algorithm for surface deformation monitoring based on small baseline differential SAR interferograms. IEEE TGRS, 40(11), 2375-2383.

Biescas, E., Crosetto, M., Agudo, M., Monserrat, O., Crippa, B., 2007. Two radar interferometric approaches to monitor slow and fast land deformation. Journal of Surveying Engineering, 133(2), 66-71.

Crosetto, M., Monserrat, O., Cuevas, M., \& Crippa, B. (2011). Spaceborne differential SAR interferometry: Data analysis tools for deformation measurement. Remote Sensing, 3(2), 305-318.

Crosetto, M., Monserrat, O., Cuevas-González, M., Devanthéry, N., \& Crippa, B. (2016). Persistent scatterer interferometry: a 
review. ISPRS Journal of Photogrammetry and Remote Sensing, 115, 78-89.

Devanthéry, N., Crosetto, M., Monserrat, O., Cuevas-González, M., Crippa, B., 2014. An approach to Persistent Scatterer Interferometry. Remote Sens., 6(7), pp. 6662-6679.

Gabriel, A. K., Goldstein, R. M., \& Zebker, H. A., 1989. Mapping small elevation changes over large areas: differential radar interferometry. Journal of Geophysical Research. Solid Earth, 94(B7), pp. 9183-9191.

Farina, P., Colombo, D., Fumagalli, A., Marks, F., Moretti, S., 2006. Permanent Scatterers for landslide investigations: outcomes from the ESA-SLAM project. Engineering Geology, 88(3), 200-217.

Ferretti, A., Novali, F., Bürgmann, R., Hilley, G., Prati, C., 2004. InSAR permanent scatterer analysis reveals ups and downs in San Francisco Bay area. Eos, Transactions American Geophysical Union, 85(34), pp. 317-324.

Ferretti, A., Monti-Guarnieri, A., Prati, C., Rocca, F., \& Massonet, D. (2007). InSAR principles-guidelines for SAR interferometry processing and interpretation (Vol. 19).

Herrera, G., Tomás, R., López-Sánchez, J. M., Montserrat, O., Cooksley, G., \& Mulas, J., 2009. Sistemas radar aplicados a la investigación de subsidencia y movimientos de ladera. Enseñanza de las Ciencias de la Tierra, 17(3), 316-324.

Massonnet, D., Feigl, K.L., 1998. Radar interferometry and its application to changes in the Earth's surface. Reviews of geophysics, 36(4), 441-500.

Massonnet, D., Sigmundsson, F., 2000. Remote sensing of volcano deformation by radar interferometry from various satellites. In: Mouginis-Mark et al. (eds), Remote sensing of active volcanism. Geophysical monograph, $116,207-221$.

Monserrat, O., Herrera, G., Barra, A., Sarro, R., López, C., Pascual, G. (2017): El proyecto SAFETY: uso de datos Sentinel-1 para la monitorización a escala regional de riesgos geológicos. In: Reducción del riesgo de desastres (Protección Civil Española). https://doi.org/10.5281/zenodo.1158579.

Mora, O., Mallorqui, J.J., Broquetas, A., 2003. Linear and nonlinear terrain deformation maps from a reduced set of interferometric SAR images. IEEE TGRS, 41(10), 2243-2253.

Notti, D., Herrera, G., Bianchini, S., Meisina, C., GarcíaDavalillo, J. C., \& Zucca, F., 2014. A methodology for improving landslide PSI data analysis. International journal of remote sensing, 35(6), 2186-2214.

Notti, D., Calò, F., Cigna, F., Manunta, M., Herrera, G., Berti, M., ... \& Zucca, F., 2015. A user-oriented methodology for DInSAR time series analysis and interpretation: Landslides and subsidence case studies. Pure and Applied Geophysics, 172(11), 3081-3105.

Rosen, P.A., Hensley, S., Joughin, I.R., Li, F.K., Madsen, S.N., Rodriguez, E., Goldstein, R.M., 2000. Synthetic aperture radar interferometry. Proceedings of the IEEE, 88(3), 333-382.
Rucci, A., Ferretti, A., Monti Guarnieri, A., Rocca, F., 2012. Sentinel 1 SAR interferometry applications: The outlook for sub millimeter measurements. Remote Sensing of Environment, 120 , pp. $156-163$.

Solari, L., Barra, A., Herrera, G., Bianchini, S., Monserrat, O., Bejar, M., Crosetto, M., Sarro, R., Salviati, P., Moretti, S., 2017. Fast detection of ground motions on vulnerable elements using Sentinel-1 InSAR data. Geomatics, Natural Hazards and Risk, 1-23

Tomás, R., Romero, R., Mulas, J., Marturià, J. J., Mallorquí, J. J., Lopez-Sanchez, J. M., ... \& Duque, S., 2014. Radar interferometry techniques for the study of ground subsidence phenomena: a review of practical issues through cases in Spain. Environmental earth sciences, 71(1), pp. 163-181.

Zerbini, S., Richter, B., Rocca, F., van Dam, T., Matonti, F., 2007. A combination of space and terrestrial geodetic techniques to monitor land subsidence: case study, the Southeastern Po Plain, Italy. J. of Geophysical Research: Solid Earth 112(B5), pp. 1978-2012.

Safety Consortium. http://safety.cttc.cat (09 February 2018) 